\title{
Predictors of adherence to tuberculosis treatment in a supervised therapy programme for prisoners before and after release
}

\author{
A. Marco*, J.A. Caylà+, M. Serra*, R. Pedro+, C. Sanrama*, R. Guerrero \\ Study Group of Adherence to Tuberculosis Treatment in Prisoners**
}

Predictors of adherence to tuberculosis treatment in a supervised therapy programme for prisoners before and after release. A. Marco, J.A. Caylà, M. Serra, R. Pedro, C. Sanrama, $R$. Guerrero, N. Ribot, Study Group of Adherence to Tuberculosis Treatment in Prisoners. CERS Journals Ltd 1998.

ABSTRACT: The prison population is a high-risk group for tuberculosis (TB). This investigation aimed to study predictive factors of treatment adherence among prisoners involved in a pilot programme of supervised treatment.

The study included TB patients from the Men's Penitentiary Center of Barcelona (MPCB) in 1995. Directly observed therapy (DOT) was carried out in the infirmary or in a methadone programme. Released prisoners were referred to the municipal maintenance methadone programmes (MMP) and other social resources. Incentives and enablers were used to improve compliance (economic aid for nutritional and housing needs, methadone programmes and admittance to a sociosanitary centre). The outcome of the patients' adherence was classified as follows: completed, defaulted, dead or transferred out. Factors associated with adherence were investigated through logistic regression.

The programme included 62 patients, 43 of whom were intravenous drug users (IVDU) and 46 were infected with the human immunodeficiency virus (HIV). Nineteen had previously had TB and 32 were released from prison during TB treatment. Overall adherence was $89 \%$; $97 \%$ among those who completed treatment in prison, and $79 \%$ among those who completed treatment outside prison $(p=0.05)$. Ninety-five per cent of IVDU in an MMP completed treatment. Homeless or alcoholic exprisoners completed treatment only if they were admitted to sociosanitary centres. DOT throughout treatment resulted in better adherence $($ odds ratio $(O R)=16.80$; confidence interval (CI): 2.42-116.2)). Those who were incarcerated throughout treatment also showed better adherence $(\mathrm{OR}=7.36$; $\mathrm{CI}: 0.79-48.16)$.

Antituberculosis treatment adherence in prisoners was high even after release with adequate co-ordination among intrapenitentiary and extrapenitentiary programmes. Maintenance methadone programmes proved very useful in intravenous drug users, as did admittance to sociosanitary centres for indigent or alcoholic exprisoners undergoing treatment.

Eur Respir J 1998; 12: 967-971.
*Medical Service, Men's Penitentiary Center of Barcelona, Spain. +Epidemiology Service, Municipal Institute of Health, Barcelona, Spain. *Health Program, Dept of Justice of Catalonia, Spain. \#Municipal Program against Drug Use, Barcelona, Spain. **J. Fernández, J. Boguña, E. Mercadé (Medical Service, Men's Penitentiary Center); LI. Torralba, N. Magrí, JM. Vázquez, E. Serres, J. Alvarós, M. Montero (Maintenance Methadone Programs of Barcelona). The investigators belong to the Tuberculosis Investigation Unit of Barcelona.

Supported by the "Fondo de Investigaciones Sanitarias de la Seguridad Social" (file 95/1696) and by the CIRIT (file 1995SGR 525).

Correspondence: J.A. Caylà, Servicio de Epidemiologia, Instituto Municipal de la Salud, Pza. Lesseps, 1, 08023 Barcelona, Spain, Fax: 3432182275

Keywords: Adherence

compliance

directly observed therapy

human immunodeficiency virus

treatment

tuberculosis

Received: August 181997

Accepted after revision April 81998
The prison population is considered a high-risk group for tuberculosis (TB) disease and infection. Even in countries with low prevalences of $\mathrm{TB}$, incidence rates in prisons are always much greater than in the general population [13].

In Spanish prisons, $40 \%$ of the incarcerated population are intravenous drug users (IVDU) [4]. IVDU were at risk for TB even before the appearance of the human immunodeficiency virus (HIV) [5] and HIV now affects 60-65\% of IVDU prisoners or $25-40 \%$ of the total prison population [6]. Given the high percentage of IVDU and the frequently resulting HIV infection, there consequently is a high prevalence of Mycobacterium tuberculosis and HIV co-infection, estimated at around $20 \%$ in some prisons [7]. Although TB is not exclusive to Spanish inmates $[1,2,8]$, it has been calculated that TB is 30 times more frequent among 15-45 yr olds in Spanish prisons than among the same age group in the population at large [4].
Both the Centers for Disease Control (CDC) [9] and, in Spain, the Conference of National Consensus for the Control of Tuberculosis have indicated the important role that prison can play in the prevention and control of TB [3]. Nevertheless, anti-TB programmes find abandonment of treatment, especially among IVDU, a major problem [10]. This is the main cause of TB relapse and resistance to the usual anti-TB drugs, a problem which is growing in the USA and is of great concern worldwide $[8,10,11]$. However, as some authors have stated [10-12], poor adherence to treatment can be modified by highly motivated health teams applying measures to ensure that medication is taken.

The objectives of this study were to determine the adherence rate to TB treatment (overall and in subgroups) and to study predictive factors of adherence to TB treatment in prisoners involved in a pilot programme based on incentives and good co-ordination among intrapenitentiary and extrapenitentiary TB programmes. 


\section{Subjects and methods}

The study included all prison inmates diagnosed with TB after systematic screening upon incarceration or during their prison stay in the Men's Penitentiary Center of Barcelona (MPCB) in 1995. To guarantee follow-up and avoid case losses once the patients were released from prison, the study was restricted to residents of Barcelona. This required good co-ordination between the TB programme of MPCB and the city's prevention and control programme.

The co-ordinated activities of the health services inside and outside the prison were based on the work of a male public health nurse of the Barcelona TB Programme who visited the prison on at least 1 day per week to review and discuss the patients with the staff of the TB programme of MPCB. This nurse followed up released prisoners, visiting their homes or sociosanitary centre and finding housing for them when necessary. Each patient was individually evaluated in order to select the best incentive. Confidential linkage between several registers, such as the Barcelona TB register and the acquired immunodeficiency syndrome (AIDS), Drug Users and Mortality registers, enabled deaths to be detected.

Screening began with the tuberculin skin test upon admission to the prison. The HIV test was voluntary for all new inmates. Those with a positive result (induration Š5 $\mathrm{mm}$ ), as well as any HIV-positive patients suspected of cutaneous anergy, underwent a radiological examination at the MPCB. Where clinical evidence was found or suspicious chest radiographic images were taken, followed by a microbiological sputum examination (Ziehl-Neelsen and Lowenstein). TB diagnosis was based on standard criteria [3]. TB cases were classified according to the recommendations of the World Health Organization (WHO), based on smear and culture results [13]. HIV infection was determined by a positive enzyme-linked immunosorbent assay (ELISA) and confirmed by Western blot.

TB cases detected during screening, along with those diagnosed during the study period among those already incarcerated, were included in a programme of supervised therapy. Four-drug therapy, as recommended by the National Conference of Consensus for the Control of Tuberculosis in Spain [3], was administered for 9 months in the HIV-positive and 6 months in the HIV-negative subjects, 2 months with isoniazid, rifampin, pirazinamide and ethambutol (2HRZE) followed by 4 or 6 months with rifampin plus isoniazid (4RH or $6 \mathrm{RH})$. Patients were considered to have abandoned treatment when they had stopped taking medication for more than 3 consecutive days and it was not possible to incorporate them back into the programme. Directly observed therapy (DOT) was the rule in prison. DOT was considered to be partial when the supervision of therapy was discontinued after release.

The following incentives were used to improve adherence. 1) IVDU were placed on a municipal maintenance methadone programme (MMP) in and out of prison. A place on MMP was reserved for those released during TB treatment. These patients were given TB medication before their methadone. 2) Economic aid for the nutritional and housing needs of exprisoners was allocated. 3) Admittance to sociosanitary centres was offered to homeless and/or alcoholic exprisoners.

To determine the predictive factors for treatment adherence, the patients who completed the treatment were compared with those who defaulted, while analysing the influence of sociodemographic variables (age, race or ethnic group, place of birth, indigence and alcoholism), clinical variables (TB antecedence and HIV infection) and drug-related variables (substance, method of drug use and treatment with methadone). To determine the rate of adherence to treatment in different groups (IVDU, indigents, etc) treatment adherence rates (completed $\times 100 / \mathrm{com}-$ pleted + defaulted) were calculated for the total number of patients and for several subgroups.

The study was closed on 31 December 1996. Data were analysed using the statistical package SPSS (SPSS Inc., Chicago, IL, USA). Predictive factors for anti-TB treatment compliance were examined with epidemiological graphics, estimation and testing (EGRET; Statistics and Epidemiology Research Corporation, Seattle, WA, USA) [14] programme. A multivariate analysis through the logistic regression model was performed for those variables that were statistically significant $(\mathrm{p}<0.05)$ on a univariate level (Chi-squared and Fisher exact tests), calculating odds ratios (OR) with $95 \%$ confidence intervals (CI).

\section{Results}

In total $62 \mathrm{~TB}$ patients were studied. They were chosen from a total of 93 cases detected from three sources: out of 3,504 prison admissions, 67 TB cases appeared (a prevalence rate of 1,912/100,000), 39 more were identified in extrapenitentiary detections and 26 TB cases were found among those already incarcerated. The 62 in question were all residents of Barcelona, and given the conditions of the correctional facility, all males, with an average age of 34 yrs $( \pm 8)$. Nineteen $(31 \%)$ had previously had TB. Thirtytwo $(51 \%)$ had been released from prison before completing TB treatment. According to WHO classification, 39\% were smear-positive pulmonary, 52\% smear-negative pulmonary and $10 \%$ extrapulmonary. Forty-three $(69 \%)$ were IVDU, 46 (74\%) HIV-positive, and 15 (24\%) HIV-negative, and for one it was impossible to perform the serology test. Comparing the HIV-positive with the HIV-negative TB patients, the former were younger, more likely to be IVDU and had had extrapulmonary TB. No statistically significant differences were found for place of birth, ethnic group or TB antecedence (table 1).

Six patients $(10 \%)$ defaulted from treatment, six $(10 \%)$ died and three (5\%) were transferred out. The overall adherence rate was $89 \%$ : $97 \%$ within prison and $79 \%$ outside prison $(\mathrm{p}=0.06)$. Among the 31 IVDU included in MMP the adherence rate was 95\% (100\% inside and 90\% outside prison). For the 22 non-IVDU, adherence was $81 \%$ (92\% inside and $70 \%$ outside) (table 2). It is worth noting that the five patients who were either homeless or alcoholic and who were admitted to a sociosanitary centre all completed treatment, whereas the three for whom admission was impossible all abandoned treatment.

The predictive factors associated with better adherence (table 3 ) in the univariate analysis were incarceration throughout treatment $(\mathrm{p}=0.05)$ and continuous supervision on DOT $(p=0.002)$. The factors that were not statistically associated were patient's origin (Spanish versus other), HIV infections (seropositive versus seronegative) and location of methadone treatment (inside versus outside prison). The multivariate analysis (table 3 ) confirmed the importance of continuous DOT, either inside or outside prison 
Table 1. - Distribution of tuberculosis (TB) cases according to several variables and human immunodeficiency virus (HIV) infection*

\begin{tabular}{|c|c|c|c|c|c|c|}
\hline \multirow[t]{2}{*}{ Variable } & \multicolumn{2}{|c|}{$\begin{array}{l}\mathrm{HIV}(+) \\
(\mathrm{n}=46)\end{array}$} & \multicolumn{2}{|c|}{$\begin{array}{c}\text { HIV(-) } \\
(\mathrm{n}=15)\end{array}$} & \multirow[t]{2}{*}{$\begin{array}{c}\text { OR } \\
(95 \% \mathrm{CI})\end{array}$} & \multirow[t]{2}{*}{ p-value } \\
\hline & $\mathrm{n}$ & $\%$ & $\mathrm{n}$ & $\%$ & & \\
\hline Average age yrs (SD) & $33(6.1)$ & & $41(11.2)$ & & & 0.001 \\
\hline \multicolumn{7}{|l|}{ Origin } \\
\hline Spanish & 40 & 80 & 10 & 20 & $3.33(0.65-16.03)$ & 0.11 \\
\hline Others & 6 & 55 & 5 & 45 & & \\
\hline \multicolumn{7}{|l|}{ Ethic group } \\
\hline White & 39 & 80 & 10 & 20 & $279(0.56-12.72)$ & 0.14 \\
\hline Other & 7 & 58 & 5 & 42 & & \\
\hline \multicolumn{7}{|l|}{ IVDU } \\
\hline Yes & 42 & 100 & 0 & 0 & Undefined & $<0.0001$ \\
\hline No & 4 & 21 & 15 & 79 & & \\
\hline \multicolumn{7}{|l|}{ Previous TB } \\
\hline Yes & 15 & 79 & 4 & 21 & $1.33(0.32-6.37)$ & 0.75 \\
\hline No & 31 & 74 & 11 & 26 & & \\
\hline \multicolumn{7}{|l|}{ TB } \\
\hline Pulmonary & 30 & 67 & 15 & 33 & $0.0(0.00-0.62)$ & 0.006 \\
\hline Not pulmonary & 16 & 100 & 0 & 0 & & \\
\hline
\end{tabular}

*: In one case it was not possible to perform a HIV serology test. OR: odds ratio; CI: confidence interval; IVDU: intravenous drug user.

$(\mathrm{OR}=16.80$; CI: $2.42-116.2)$ and the entire treatment administered during prison stay (OR $=7.36$; $\mathrm{CI}$ : 0.79-68.16) as predictors of greater adherence to anti-TB treatment.

\section{Discussion}

TB in prisons is a serious public health problem. The present study, and similar studies [7] revealed a prison TB prevalence rate of 2,000/100,000 inmates. This study demonstrates that with good co-ordination among intrapenitentiary and extrapenitentiary programmes a high rate of adherence to TB treatment $(97 \%$ in prison and $79 \%$ after release) could be achieved. Continuous DOT inside and outside prison was found to be the best predictor of compliance with TB treatment in this difficult population.

The WHO calculated that between 1990 and 1999, 90 million new cases and 30 million death, the majority in developing countries, will occur unless appropriate measures such as supervised therapy programmes [15] are put into action. In poor countries it is estimated that every year there are 400 new cases per 100,000 inhabitants. In Africa and south-east Asia, recent years have seen a serious rise in incidence [16]. Developed countries have also witnessed high incidences in pockets of large cities and in correctional facilities $[2,9,16,17]$. In the USA the incidence of TB had been falling until 1984, but between 1985 and 1992 there was a 20\% [17] increase, due to HIV infection. Worldwide, an estimated 6 million people are co-infected with HIV and TB. In Spain, one of the European countries that is most affected by AIDS and TB [18], the incidence of TB is 40-60/100,000 [19, 20] and the situation within prisons is always much worse.

Although TB is both preventable and curable with correct therapy, it requires a prolonged treatment period, too often resulting in nonadherence. In 1994, only 53\% of IVDU [20] in Barcelona (the site of the penitentiary centre chosen for this study) completed anti-TB therapy. Homeless and alcoholic subjects also had a low adherence to treatment [21]. Abandonment causes relapses and on occasion, microepidemics of drug-resistant TB, particularly among HIV-positive patients, as much in the community $[22,23]$ as in prisons [7, 24]. If anti-TB treatment adherence is similar to that of the general population for any other therapy (50\%) [25], the situation could become extremely serious in the coming years. Therefore, it is advisable to offer incentives [21] to poor adherence groups. It has even been debated whether hospital admission [26] be required or legal action taken to detain noncompliant patients [27], so that DOT can be ensured. Both the WHO

Table 2. - Adherence rate according to risk factor and place of completion of treatment

\begin{tabular}{|c|c|c|c|c|c|c|c|}
\hline \multirow{3}{*}{ Risk factors } & \multicolumn{3}{|c|}{ In prison } & \multicolumn{3}{|c|}{ Out of prison } & \multirow{3}{*}{$\begin{array}{c}\text { Global AR } \\
\%\end{array}$} \\
\hline & \multicolumn{2}{|c|}{ Completed } & \multirow{2}{*}{$\begin{array}{c}\mathrm{AR} \\
\%\end{array}$} & \multicolumn{2}{|c|}{ Completed } & \multirow{2}{*}{$\begin{array}{c}\mathrm{AR} \\
\%\end{array}$} & \\
\hline & Yes & No & & Yes & No & & \\
\hline$\overline{\text { IVDU }}$ & 17 & 0 & 100 & 12 & 2 & 86 & 94 \\
\hline In MMP & 11 & 0 & 100 & 9 & 1 & 90 & 95 \\
\hline Not in MMP & 6 & 0 & 100 & 3 & 1 & 75 & 90 \\
\hline Homeless & 8 & 0 & 100 & 5 & 3 & 63 & 81 \\
\hline \multicolumn{8}{|l|}{ Resident* } \\
\hline Yes & & & & 5 & 0 & 100 & 100 \\
\hline No & & & & 0 & 3 & 0 & 0 \\
\hline Others & 3 & 1 & 75 & 2 & 0 & 100 & 83 \\
\hline Total & 28 & 1 & 97 & 19 & 5 & 79 & 89 \\
\hline
\end{tabular}

\footnotetext{
*: Sociosanitary residential centre. AR: adherence rate; IVDU: intravenous drug user; MMP: maintenance methadone programme.
} 
Table 3. - Study of factors associated with adherence to antituberculosis treatment in inmates

\begin{tabular}{|c|c|c|c|c|c|c|c|c|}
\hline \multirow{2}{*}{ Variable } & \multicolumn{2}{|c|}{ Completed } & \multicolumn{2}{|c|}{ Defaulted } & \multirow{2}{*}{$\begin{array}{c}\text { OR } \\
(95 \% \mathrm{CI})\end{array}$} & \multirow{2}{*}{ p-value } & \multirow{2}{*}{$\begin{array}{l}\text { Adjusted OR } \\
(95 \% \mathrm{CI})\end{array}$} & \multirow{2}{*}{$\mathrm{p}$-value } \\
\hline & $\mathrm{n}$ & $\%$ & $\mathrm{n}$ & $\%$ & & & & \\
\hline \multicolumn{9}{|l|}{ Origin } \\
\hline Spanish & 37 & 86 & 6 & 14 & $0.00(0.00-3.75)$ & 0.26 & _- & \\
\hline Other & 10 & 100 & 0 & 0 & & & & \\
\hline \multicolumn{9}{|l|}{ HIV infection } \\
\hline Yes & 35 & 92 & 3 & 8 & $1.94(0.14-18.95)$ & 0.40 & - & \\
\hline No & 12 & 86 & 2 & 14 & & & & \\
\hline \multicolumn{9}{|l|}{ Entire treatment* } \\
\hline Yes & 28 & 97 & 1 & 3 & $7.37(0.72-360.6)$ & 0.05 & $7.36(0.79-68.16)$ & 0.07 \\
\hline No & 19 & 79 & 5 & 21 & & & & \\
\hline \multicolumn{9}{|l|}{ Methadone } \\
\hline In prison & 11 & 95 & 0 & 5 & Undefined & 0.47 & - & \\
\hline Out of prison & 9 & 85 & 1 & 15 & & & & \\
\hline \multicolumn{9}{|l|}{$\mathrm{DOT}^{+}$} \\
\hline Yes & 12 & 100 & 0 & 0 & Undefined & 0.002 & $16.80(2.42-116.2)$ & 0.004 \\
\hline No & 0 & 91 & 3 & 9 & & & & \\
\hline
\end{tabular}

*: administered during prison stay; +: continuous DOT in or outside prison. DOT: directly observed therapy; HIV: human immunodeficiency virus; OR: odds ratio; CI: confidence interval.

and the American Thoracic Society [28] recommend DOT as a demonstrated way to reduce treatment nonadherence, relapses and anti-TB drug resistance [11].

It is important to take into account that the present study dealt with typically poor-adherence groups $(62 \%$ were IVDU and $28 \%$ were either homeless and/or alcoholic), and that a high percentage of patients $(31 \%)$ had previously had TB and most had probably never completed treatment. There was an adherence rate of $89 \%$, which was far higher than that for these groups in Barcelona and in line with the rate for the city as a whole (90\%) [20]. Such high adherence was achieved with incentives and enablers for the affected people and, most importantly, with the collaboration of the entities attending these generally low-adherence groups (prisons, drug-dependence centres and the Barcelona TB control programme). All of these contributed to keeping patients on treatment. The study depended on workers from public assistance facilities and only US\$2,000 was needed for economic aid, a far lower cost than that calculated in other studies as the real cost incurred when treatment is abandoned [29].

Adherence within prisons, all but guaranteed with motivated health teams, was outstanding. The best incentive for IVDU was not economic, but rather inclusion in an MMP. Ninety-five per cent of users completed treatment under such conditions, a higher percentage than in New York, with a similar population [30]. For homeless or alcoholic patients, adherence was good in prison, but null upon release, except when patients were given shelter in sociosanitary centres that could ensure DOT. Of note is that no statistically significant difference appeared in compliance between Spanish and foreign patients, thus dispensing with the need to adopt measures based on demographic factors, which could give rise to discriminatory attitudes [31].

In conclusion, tuberculosis in prison should be controlled through directly observed therapy programmes that ensure adherence, especially in low-adherence groups such as intravenous drug users, alcoholics and the homeless. Collaboration among both intrapenitentiary and extrapenitentiary tuberculosis programmes is essential in achieving high rates of adherence to antituberculosis therapy, since patients frequently are released from prison before the completion of treatment ( $52 \%$ in the present case). Main- tenance methadrome programmes are highly effective for adherence among intravenous drug users, and are also very useful in preventing infection with the human immunodeficiency virus, as they break the habit of sharing injection material [32, 33]. Homeless and alcoholic tuberculosis patients must be admitted to sociosanitary centres to follow-up directly observed therapy if they are released from prison before antituberculosis treatment is completed.

\section{References}

1. Bellin E, Fletcher D, Safyer S. Abnormal chest X-rays in intravenous drug users: implications for tuberculosis screening programs. Am J Public Health 1993; 83: 35-40.

2. Salive ME, Viahov D, Brewer TF. Coinfection with tuberculosis and HIV-1 in male prison inmates. Public Health Rep 1990; 105: 307-310.

3. Grupo de Trabajo sobre Tuberculosis. Conseno Nacional para el control de la tuberculosis en España. Med Clín (Barc) 1992; 98: 24-31.

4. Martín Sánchez M. Programa de Prevención y Control de Enfermedades Transmisibles en instituciones Penitenciarias. Revista de Estudios Penitenciarios. Monográfico de Sanidad Penitenciaria. Madrid-Extra-1-1990; pp. 51-67.

5. Reichman LB, Felton ChP, Edsall JR. Drug dependence, a possible new risk factor for tuberculosis disease. Arch Intern Med 1979; 139: 337-339.

6. March A, Martin V, Garrote G. SIDA y población reclusa en España. Jano 1996; 50: 36-41.

7. Martín V, González P, Caylà JA, et al. Case-finding of pulmonary tuberculosis on admission to a penitentiary centre. Tuberc Lung Dis 1994; 75: 49-53.

8. Valway SE, Richards SB, Kovacovich J, Greifinger RB, Crawford JT, Dooley SW. Outbreak of multi-drug-resistant tuberculosis in a New York State prison, 1991. Am J Epidemiol 1994; 140: 113-122.

9. Centers for disease Control and Prevention. Prevention and control of tuberculosis in correctional institutions: recommendations of the Advisory Committee for the Elimination of Tuberculosis. Morb Mortal Wkly Rep 1989; 18: 313-321.

10. Curtis R, Friedman SR, Neaigus A, Jose B, Goldstein M, Des Jarlais DC. Implications of directly observed therapy in tuberculosis control measures among IDUs. Public Health Rep 1994; 109: 319-327. 
11. Weis SE, Slocum PC, Blais FX, et al. The effect of directly observed therapy on the rates of drug resistance and relapse in tuberculosis. N Engl J Med 1994; 330: 1179-1184.

12. Menzies R, Rocher I, Vissandjee B. Factors associated with compliance in treatment of tuberculosis. Tuberc Lung Dis 1993; 74: 32-37.

13. WHO. Framework for effective tuberculosis control. WHO/TB/1994; 179: 1-13.

14. Epidemiological graphics, estimation and testing package (EGRET). Seattle, WA, Statistics and Epidemiology Research Corperation, 1990.

15. World Health Organization. WHO report on the tuberculosis epidemic 1997. Geneva: World Health Organization, 1997.

16. Raviglione MC, Snider DE Jr, Kochi A. Global epidemiology of tuberculosis: morbidity and mortality of a worldwide epidemic. JAMA 1995; 273: 220-226.

17. Centers for Disease Control and Prevention. Tuberculosis morbidity- United States, 1992. Morb Mortal Wkly Rep 1993; 42: 696-704.

18. World Health Organization. World health statistics annual 1992. Geneva, World Health Organization, 1993.

19. Caminero JA. Tuberculosis and respiratory infections scientific area (SEPAR). Update of the infection and tuberculosis disease in Spain (1988-1992). Tuberc Lung Dis 1994; 75: Suppl., 69-70.

20. Caylà JA, Galdós-Tangüis, García de Olalla P, Brugal T, Jansà JM, Miranda PSC. La Tuberculosis en Barcelona. Informe 1994. Barcelona, Publicaciones del instituto Municipal de la Salud, 1995.

21. Pozsic CJ. Compliance with tuberculosis therapy. Med Clin North Am 1993; 77: 1289-1301.

22. Frieden TR, Sterling T, Pablos-Méndez A, Kilburn JO, Cauthen GM, Dooley SW. The emergence of drug-resistant tuberculosis in New York City. N Engl J Med 1993; 328: 521-526.
23. Bloch $\mathrm{AB}$, Cauthen GM, Onorato IM, et al. Nationwide survey of drug-resistant tuberculosis in the United States. JAMA 1994; 271: 665-671.

24. Centers for Disease Control and Prevention. Transmission of multidrug-resistant tuberculosis among immunocompromised persons in a correctional system. New York, 1991. Morb Mortal Wkly Rep 1992; 41: 507-509.

25. Wright EC. Non compliance. Or how many aunts has Matilda? Lancet 1993; 342: 909-913.

26. Yew WW, Chau C-H, Tse L-S. Does hospitalizing patients with tuberculosis ensure compliance with drug regimens? Clin Infect Dis 1994; 19: 554-555.

27. Frieden TR, Fujiwara PI, Washko RM, Hamburg MA. Tuberculosis in New York City. Turning the tide. $N$ Engl $J$ Med 1995; 333: 229-233.

28. American Thoracic Society. Treatment of tuberculosis and tuberculosis infection in adults and children. Am J Respir Crit Care Med 1994; 149: 1359-1374.

29. Chaulk CP, Moore-Rice K, Rizzo R, Chaisson RE. Eleven years of community-based directly observed therapy for tuberculosis. JAMA 1995; 274: 945-951.

30. Gourevitch MN, Wasserman W, Panero MS, Selwin PA. Successful adherence to observed prohylaxis and treatment of tuberculosis among drug users in a methadone program. J Addict Dis 1996; 15: 93-104.

31. Sumartojo E. When tuberculosis treatment fails: a social behavioral account of patient adherence. Am Rev Respir Dis 1993; 147: 1311-1320.

32. Cooper JR. Methadone treatment and acquired immunodeficiency syndrome. JAMA 1989; 262: 1664-1668.

33. Selwin PA, Hartel D, Wasserman W, Drucker E. Impact of the AIDS epidemic on morbidity and morality among intravenous drug users in a New York city methadone maintenance program. Am J Public Health 1989; 79: 1358-1362. 